Full paper

\title{
Diffusion (DOSY) 1H NMR as an alternative method for molecular weight determination of polyethylene furanoate (PEF) polyesters
}

Jan-Georg Rosenboom, Jonathan de Roo, Giuseppe Storti, Massimo Morbidelli*

J.-G. Rosenboom, Prof. G. Storti, Prof. M. Morbidelli

ETH Zurich, Institute for Chemical and Bioengineering, 8093 Zurich, Switzerland

E-mail: massimo.morbidelli@chem.ethz.ch

Dr. J. de Roo

Ghent University, Department of Inorganic and Physical Chemistry, Krijgslaan 281 S3, 9000

Ghent, Belgium

Polyethylene furanoate $(\mathrm{PEF})$ is a promising $100 \%$ biomass-derived alternative to polyethylene terephthalate (PET), but challenges all solution characterization methods due to its insolubility in most common solvents. Diffusion (DOSY) ${ }^{1} \mathrm{H}$ NMR can be an alternative, reliable and fast method to analyze molecular weights of PEF polyesters. Calibration with PET standards yields excellent agreement of DOSY predictions with the absolute $M_{n}$ and $M_{w}$ values obtained via size exclusion chromatography (SEC) equipped with multi-angle light scattering (MALS) detector in the range of commercial relevance $\left(\mathrm{M}_{\mathrm{w}}<100,000 \mathrm{~g} \mathrm{~mol}^{-1}\right)$. Mean square displacement analysis shows unhindered molecular diffusion for all tested concentrations (from 0.4 to $30 \mathrm{mg} \mathrm{mL}^{-1}$ ). The DOSY procedure can be optimized towards shorter analysis times (down to $1 \mathrm{~min}$ ) and a more straightforward implementation, making it a powerful and fast tool for molecular weight analysis in the laboratory as well as in industrial process applications. 
FIGURE FOR ToC_ABSTRACT

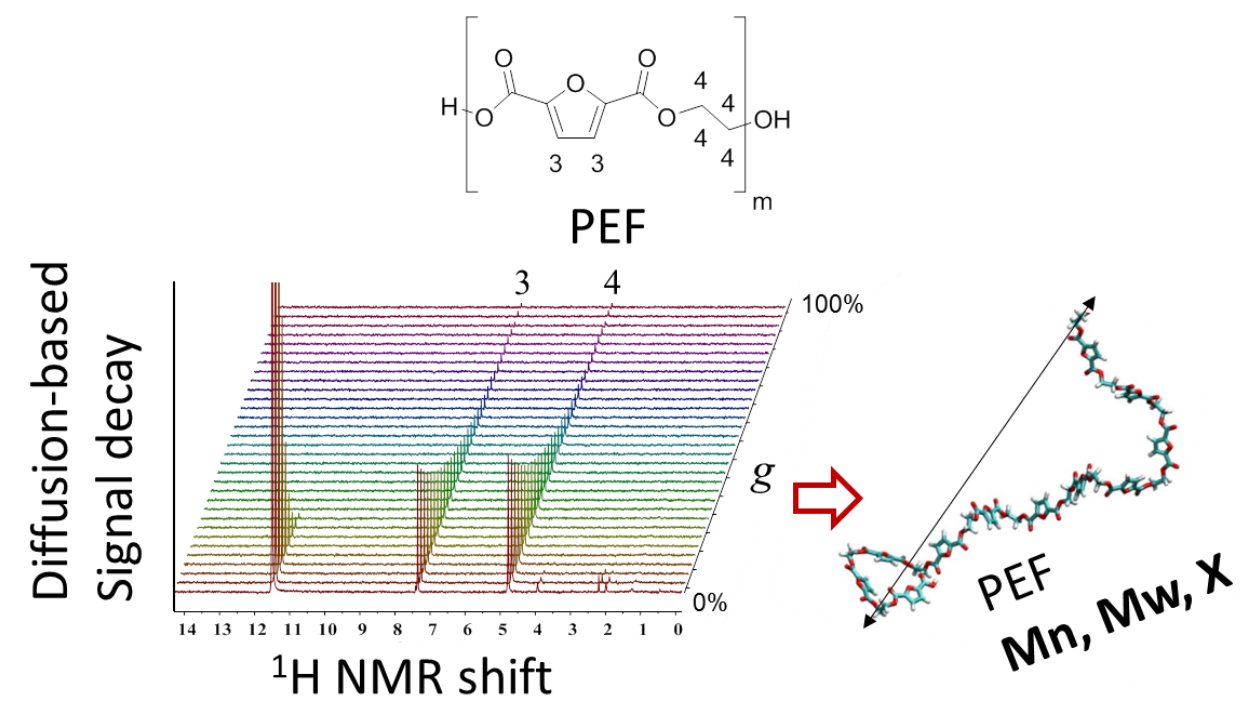




\section{Diffusion, DOSY NMR, molecular weight analysis, furanic polyesters, poly(ethylene furanoate)}

\section{Introduction}

Furanic polymers have been identified among the top potential chemicals from biomass by the US-DOE in 2004 and have gained interest as substitutes for oil-derived polyesters ever since. ${ }^{[1]}$ In particular, polyethylene terephthalate (PET; repeating unit in Figure 1), one of the world's most dominant oil-based plastics, can potentially be replaced with $100 \%$ bio-based polyethylene furanoate (PEF; repeating unit in Figure 1) that has already shown superior material properties. ${ }^{[2-9]}$ As for most polymers, the molecular weight is a key property, qualifying the material for commercial application. Several companies are developing PEF grades for applications in textiles or to replace PET bottles, requiring number-average $\left(\mathrm{M}_{\mathrm{n}}\right)$ and weight-average $\left(\mathrm{M}_{\mathrm{w}}\right)$ average molecular weights of $30,000 \mathrm{~g} \mathrm{~mol}^{-1}$ and $60,000 \mathrm{~g} \mathrm{~mol}^{-1}$ respectively. Traditionally, PEF is produced by polycondensation and solid state postcondensation, yielding sufficiently high molecular weights but limited by condensation byproduct removal and thus requiring very long reaction times (in the order of days ${ }^{[3,4,6,7]}$ ). Alternatively, we have been developing a process based on ring-opening polymerization (ROP), which delivers sufficiently high molecular weight PEF in significantly shorter times without any tedious byproduct removal ${ }^{[10-12]}$. The feasibility of intermediate molecular weight synthesis by ROP has been recently confirmed by Morales-Huerta et al. $(2016)^{[13]}$.

For both PET and PEF, molecular weight determination is quite problematic due to their insolubility in most common solvents. Hot tetrachloroethane, trifluoroacetic acid (TFA) and hexafluoro-2-propanol (HFIP) are the only suitable solvents for these polymers. Although size exclusion chromatography (SEC) analysis is possible with HFIP, it requires complex HFIP- 
resistant equipment, highly advanced experimental care, health and safety precautions and continuous HFIP recovery as this solvent is expensive. ${ }^{[14,15]}$ End-group analysis by NMR is a simple method to measure number-based molecular weight, but is limited to lower molecular weights for which end-groups are still detectable in the NMR spectrum. Therefore, other analytical methods suitable to reliably measure the molecular weight of polyesters such as PET and PEF are urgently needed.

Diffusion ordered spectroscopy (DOSY) nuclear magnetic resonance (NMR), also known as pulsed-gradient spin echo (PGSE) NMR, has been established in recent years as an accurate method to measure the size of colloidal nanocrystals ${ }^{[16,17]}$, proteins $^{[18]}$ and polymers ${ }^{[15,19,20]}$. DOSY NMR applies pulsed field gradients for a spatial labelling of molecules to track their translational motion. In addition to the usual homogeneous magnetic field for 1-dimensional ${ }^{1} \mathrm{H}$ NMR analysis, DOSY applies a z-dependent field gradient $\mathrm{g}(\mathrm{z})$ for a gradient time $\delta$ causing the spins to precess with different frequencies, depending on their position in the sample tube. After a diffusion time $\Delta$, their positions can be decoded using an opposite gradient $-\mathrm{g}(\mathrm{z})$, which would completely refocus the frequency evolution in the case of a static system, neglecting relaxation ${ }^{[22]}$. However, since in between the two gradient pulses the molecules are moving due to diffusion, the local field experienced by the spins during the second pulse will not match the first one, which leads to only partial refocusing of the magnetization vectors. Consequently, the resonance signal intensity will be attenuated proportionally to the diffused path of the molecule, and thus to its diffusion coefficient $D$. The faster the molecules move, the faster their intensity decreases.

Whereas DOSY NMR has been applied to polymers, the weight-average molecular weights $\mathrm{M}_{\mathrm{w}}$ estimated by DOSY and by SEC were only in good agreement when both calibration standards and samples were of the same polymer type, and mostly with a polydispersity of approximately $1^{[15,19-21]}$. The respective polymers analyzed in the literature were polystyrene 
(PS) ranging from $\mathrm{M}_{\mathrm{w}}=9000$ to $200000 \mathrm{~g} \mathrm{~mol}^{-1}$ in benzene- $d_{6}{ }^{[15]}$, poly(urea-urethane) copolymers around $\mathrm{M}_{\mathrm{w}}=30000 \mathrm{~g} \mathrm{~mol}^{-1}$ in dichloromethane- $d_{2}{ }^{[19]}$, polylactic acid (PLA) ranging from $\mathrm{M}_{\mathrm{w}}=4000$ to $33000 \mathrm{~g} \mathrm{~mol}^{-1}$ in benzene- $d_{6}{ }^{[20]}$, and polyethylene oxide ranging from $\mathrm{Mw}=1000$ to 500000 in $\mathrm{D}_{2} \mathrm{O}^{[21]}$. However, $\mathrm{PEF}$ is not yet an established polymer and PEF standards are not available. Furthermore, PET and PEF are commonly found with a polydispersity of about 2 as typical of the polymerization mechanisms by which they are produced, polycondensation or living ring-opening polymerization ${ }^{[6,10,13,23]} \cdot \mathrm{M}_{\mathrm{n}}$ has so far mostly been assessed by ${ }^{1} \mathrm{H}$ NMR end-group analysis, which is infeasible for higher molecular weight polymers where end-groups are invisible ${ }^{[15,20]}$. Simultaneous characterization of both $\mathrm{M}_{\mathrm{n}}$ and $\mathrm{M}_{\mathrm{w}}$ of polydisperse polyesters such as PET and PEF using DOSY NMR has not been performed yet, especially not where calibrant and analyte differed.

The aim of this work is to explore the applicability of NMR DOSY to the measurements of PEF molecular weights. The effects of sample preparation with respect to concentration and solvent, calibration with appropriate standards, as well as pulse program features and the associated analysis time, are discussed. The technique was validated by comparing the DOSY-based molecular weight values with those obtained by absolute molecular weight measurements from SEC with MALS (Multiangle Light Scattering).

\subsection{Methodology}

A diffusion coefficient $D$ is derived from DOSY by fitting the signal attenuation as a result of the dislocation of molecules due to diffusion, the spin magnetization vectors of which had previously been labelled through pulse field gradients. The relative attenuation of this signal $\mathrm{I} / \mathrm{I}_{0}$ has first been described by Stejskal and Tanner ${ }^{[24]}$ and later generalized for any DOSY pulse program by Sinnaeve ${ }^{[22]}$. For the double stimulated echo pulse program with monopolar 
pulses and smoothed squared gradient shapes (used in this paper) the Stejskal-Tanner equation is

$$
I=I_{0} e^{-(\gamma \delta g \xi)^{2} D(\Delta-\delta / 3)}
$$

with the gyromagnetic ratio of the observed ${ }^{1} \mathrm{H}$ nucleus $\gamma$, the gradient pulse length $\delta$, the gradient strength $g$, the diffusion time $\Delta$ and the diffusion coefficient $D$. The shape factor $\xi$ depends on the gradient shape but this is usually already corrected for in the gradient value by the Bruker software, TOPSPIN. The Stejskal-Tanner equation for other pulse programs is only slightly different and the impact on the diffusion coefficient is very small in the case of long diffusion times $(\Delta>250 \mathrm{~ms})$. In a real DOSY experiment, values of $\Delta$ and $\delta$ are set while varying $g$ to derive decay curves of $I$ to fit $D$. Further accounts on NMR DOSY can be found in the literature. ${ }^{[25,26]}$

Diffusion is mainly affected by temperature, viscosity of the solution and particle size. These effects are summarized by the Stokes-Einstein equation, assuming relatively large and spherical particles at infinite dilution:

$$
D=\frac{k_{B} T}{6 \pi \eta r_{S}}
$$

where $k_{B}$ is the Boltzmann constant, $T$ the absolute temperature, $\eta$ the temperature dependent viscosity of the solution and $r_{S}$ the solvodynamic radius of the spherical particle. ${ }^{[26]}$ Since temperature clearly affects the diffusion measurement, a careful temperature control is essential during DOSY. In the case of macromolecules, $D$ is a function of the molecular weight and can be expressed by a modified version of the Mark-Houwink-Sakurada equation (where randomly coiled spherical chain is assumed): ${ }^{[20]}$

$$
D=K M W^{a}
$$


$K$ and $a$ are scaling parameters dependent on the polymer-solvent-system that are determined during calibration with standards. The logarithmic form of equation 3 usually serves to describe the linear calibration to correlate molecular weight with diffusion. Viscosity and molecular crowding (not accounted for in equation 2) hinder diffusion, and are directly correlated with the sample concentration. Conventional ${ }^{1} \mathrm{H}$ NMR experiments are usually performed at higher sample concentrations to detect trace signals of present compounds. In contrast, for DOSY measurements of polymers, generally high dilution of the sample is advised to avoid any effect of polymer concentration on viscosity and to ensure operation where molecules can diffuse randomly without interaction. ${ }^{[15]}$ DOSY performance, accuracy and reproducibility are mainly defined by the quality of the intensity decay curve. Therefore, as for most analytical techniques, signal-to-noise is an important aspect in DOSY NMR. This signal-to-noise is enhanced by repeated measurements (i.e., several number of scans) for lower sample concentrations, however, at the expense of longer experiment times.

Due to its insolubility in most common solvents, the solvent selection for PET and PEF is limited to quite specific solvents such as HFIP- $d_{2}$ and TFA- $d$. HFIP and TFA have higher viscosities $\left(\eta_{\text {HFIP }}=1.63 \mathrm{cP}, \eta_{\text {TFA }}=0.81 \mathrm{cP}\right)$ compared with the viscosity of, e.g., benzene $\left(\eta_{\text {Benzene }}=0.6 \mathrm{cP}\right)$. As a consequence, the diffusion time needs to be longer to reach full attenuation at the highest gradient strength, reducing the signal-to-noise due to relaxation. This presents challenges for samples with low concentrations of high molecular weight polymers, in which case temperature could be exploited to facilitate the measurement.

\section{Experimental Section}

All NMR DOSY experiments were recorded on a Bruker Avance III 400 MHz Spectrometer, equipped with a $5 \mathrm{~mm}$ PABBO probe head. All NMR samples were equilibrated at the measurement temperature of $298 \mathrm{~K}$ for $5 \mathrm{~min}$ before data collection. Spinning was deactivated 
to avoid convection. Each NMR tube was filled with $0.4 \mathrm{mg} \mathrm{mL}^{-1}$ of polymer in $0.75 \mathrm{~mL}$ deuterated solvent. One dimensional (1D) ${ }^{1} \mathrm{H}$ spectra were acquired with the zg30 pulse program from the Bruker library. 2D DOSY spectra were acquired using a double stimulated echo sequence (“dstegp2s”) for convection compensation and with monopolar gradient pulses $^{[16,27]}$. Smoothed rectangle gradient pulse shapes were used throughout. Standard decay curves were recorded with 32 increments of quadratic gradient strength distribution from 2$95 \%$ of the probe's maximum value. The maximum gradient strength was $0.46 \mathrm{~T} \mathrm{~m}^{-1} \cdot 16$ dummy scans and 16 acquisition scans were performed for each experiment with the gradient pulse duration and diffusion time $\Delta$ optimized to ensure a full $(5 \%)$ signal attenuation of the signal in the final increment relative to the first increment. 16k data points were sampled with the spectral width set to $12 \mathrm{ppm}$ and a relaxation delay (D1) of $1 \mathrm{sec} .90$ degree pulses (P1) were optimized for $\mathrm{P} 1_{\mathrm{PET}}=15.75 \mu$ s and for $\mathrm{P} 1_{\mathrm{PEF}}=16.2 \mu$ s to achieve maximum signal. The DOSY spectra were multiplied with an exponential window function before fourier transformation (xf2) and subsequently phase corrected. The diffusion coefficients were obtained by fitting the Stejskal-Tanner equation using the T1/T2 analysis module of Topspin 1.3 to the signal intensity decay. Certain experiments were performed to explore analysis time optimization: (i) a constant value of $\Delta=600 \mathrm{~ms}$ was used for all different standards and samples or (ii) less gradient strength increments or (iii) less acquisition scans were used.

Absolute molecular weight $\left(\mathrm{M}_{\mathrm{w}}, \mathrm{M}_{\mathrm{n}}\right)$ analyses of PET and PEF samples were performed on an Agilent 1100 GPC using two PFG linear M columns (PSS) connected in series with an Agilent $1100 \mathrm{VWD} / \mathrm{UV}$ detector operated at $290 \mathrm{~nm}$, a DAWN HELEOS II multiangle laser light scattering (MALS) detector (Wyatt Technology Europe) followed by an Agilent 1100 RID detector. Samples were eluted in 1,1,1,3,3,3-Hexafluoisopropanol with 0.02 M Potassium Trifluoroacetate (KTFAc) at $1 \mathrm{~mL} \mathrm{~min}^{-1}$ at room temperature. Conversion was evaluated with PSS WinGPC Unichrom software as the UV signal area fraction of PEF area integral versus 
total sample area. Absolute molecular weights were evaluated with Wyatt ASTRA software and dn/dc values for PET and PEF derived with our analytical setup, specifically the Agilent 1100 RID detector. The dn/dc for PET yielded molecular weight predictions matching well the expected standard specifications supplied by the manufacturer, thus confirming the functionality of our SEC-MALS setup to derive absolute molecular weights.

The deuterated solvents Trifluoroacetic Acid- $d$ and 1,1,1,3,3,3-Hexafluoisopropanol- $d_{2}$ were purchased from Cambridge Isotope Laboratories, USA, and used as received. PET standards were received from PSS Polymer Standards Service, Germany. PET bottle samples were taken from commercially available bottles. PEF samples were synthesized in our laboratories via ring-opening polymerization of cyclic monomers.

\section{Results and Discussion}

\subsection{Calibration and Validation}

The diffusion coefficients of PET and PEF polymers can readily be measured in TFA- $d$ by DOSY using standard settings and with optimized diffusion times $\Delta$ and gradient lengths $\delta$. Figure 2 shows the well-separated ${ }^{1} \mathrm{H}$ chemical shifts of the TFA solvent peak and the Furanand Ethylene Glycol (EG)-protons in PEF in a typical stack of 32 gradient strength increments. Both PEF resonances can be used for fitting their decay curve to the ST equation. However, PEF standards for calibration are not available, and therefore, we deemed PET standards the appropriate choice due to its similar structure and size distribution characteristics. In fact, PET standards can be used well for DOSY calibration, but not for size exclusion chromatography (SEC) calibration. Initially applied SEC analysis of our PEF samples using PET standards resulted in an overprediction of molecular weight by roughly 2 2.5 fold, compared with SEC analysis evaluated with MALS as an absolute molecular weight 
method. Similar overprediction was found using polymethylmetacrylate (PMMA) and polystyrene (PS) standards. The reason behind this may be the different coiling behavior and hydrodynamic radius of PET and PEF, which causes a PET polymer chain to be retained much more by the pores of a SEC column than a PEF chain of the same molecular weight. This effect is not present in DOSY, where the molecular weight rather than the coiling seems to affect diffusion: PET and PEF molecules of the same (absolute) molecular weight do show the same diffusion coefficient, e.g. $D=3.2 \cdot 10^{-11} \mathrm{~m}^{2} \mathrm{~s}^{-2}$ (by DOSY) for both PET and PEF of about $61000 \mathrm{~g} \mathrm{~mol}^{-1}$ (by MALS), as shown in Table 1. Therefore, PET can be used as a calibrant for PEF in DOSY, but not using SEC.

From the corresponding decay curves of known absolute molecular weight PET standards (see supporting information), diffusion coefficients were derived and a calibration curve was established (Figure 3). Since PET standards, similar to PEF products, feature a polydispersity $\approx 2$, separate calibration curves for number-average molecular weight, $\mathrm{M}_{\mathrm{n}}$, and weightaverage molecular weight, $\mathrm{M}_{\mathrm{w}}$, are presented in Figure 3. Recently, Kuz'mina et al. followed a similar approach, assigning different molecular weight averages $\left(M_{n}, M_{w}, M_{p}\right)$ of hydroxyethyl starch (HES) to its diffusion coefficient for the analysis of other HES samples of the same type, where the error between DOSY and SEC prediction was below 20\%. ${ }^{[28]}$ Calibration using polydisperse samples of one polyester applied to another polyester has not been reported yet. The obtained curves yield a linear log-log relation of molecular weights to the diffusion coefficient (in accordance with theory, see equation 3) in a range of about 10 to $115 \mathrm{~kg} \mathrm{~mol}^{-1}$, covering high molecular weights relevant for bottle and other typical PET applications.

We sought to apply this calibration to unknown PEF and PET samples and validate the analysis method via size exclusion chromatography coupled with multi-angle light scattering (SEC-MALS). First, PET standards with known molecular weights were measured by SEC- 
MALS and the obtained values matched the specifications of the standards, confirming the accuracy of SEC-MALS (see Table 1). Second, commercial PET bottles of different suppliers and unknown PEF samples from our syntheses were measured in both DOSY and SECMALS. The average molecular weights $\left(\mathrm{M}_{\mathrm{n}}\right.$ and $\left.\mathrm{M}_{\mathrm{w}}\right)$ were derived from DOSY, using the above calibrations. As shown in Figure 4 and Table 1, there is an excellent one-to-one correlation between the DOSY and the SEC-MALS data, for all PET standards and unknown PEF and PET samples. This confirms the ability of DOSY to accurately determine $\mathrm{M}_{\mathrm{n}}$ and $\mathrm{M}_{\mathrm{w}}$ of PEF after calibration with PET standards of known molecular weight. Furthermore, the PET bottles from different suppliers showed the same trend of differences in molecular weight (from 57,000 to $61,000 \mathrm{~g} \mathrm{~mol}^{-1}$ ) in both SEC-MALS and DOSY, which confirms that DOSY can compete with MALS on resolution.

The PEF samples of different molecular weights were obtained during and after synthesis via ring-opening polymerization of cyclic oligoesters. Interestingly, the ${ }^{1} \mathrm{H}$ NMR resonances of the PEF product and the cyclic monomers, especially the furan signal, exhibit different chemical shifts. This enables simultaneous molecular weight analysis (via DOSY) and conversion analysis (via regular $1 \mathrm{D}{ }^{1} \mathrm{H}$ NMR). Figure 5 shows the ${ }^{1} \mathrm{H}$ NMR spectrum of a PEF sample taken from the ROP reactor. DOSY fitting of the isolated peak associated with PEF product (3a) supplies values $\left(D=4.5710^{-11} \mathrm{~m}^{2} \mathrm{~s}^{-1} ; \mathrm{M}_{\mathrm{n}}=16,600 \mathrm{~g} \mathrm{~mol}^{-1}, \mathrm{M}_{\mathrm{w}}=32,200 \mathrm{~g}\right.$ $\left.\mathrm{mol}^{-1}\right)$ very close to those derived from SEC-MALS $\left(16,100 \mathrm{~g} \mathrm{~mol}^{-1} ; 31,900 \mathrm{~g} \mathrm{~mol}^{-1}\right)$, thus confirming that accuracy of molecular weight analysis of PEF samples at lower conversion with DOSY is not affected by the cyclic monomers present during the reaction. The conversion of this sample, derived as the ratio of the PEF integral (3a) and the integral sum of both PEF and cyclic monomer $(3 a+3 b)$, was estimated to be $X=43.4 \%$, which is close to $X=$ 42.3\% as derived from SEC analysis with UV concentration detector. With shortened DOSY 
time down to minutes, as discussed later, this method can be interesting for online kinetic measurements.

Having confirmed the validity of DOSY for molecular weight analysis, the next question was whether the standard analysis parameters and procedure could be optimized. We explored the influence of sample concentration, measurement time, and solvent use. Finally, we discuss some challenges associated with very large molecular weights.

\subsection{Effect of concentration}

In general, DOSY NMR samples should be highly diluted to avoid molecular crowding and viscosity effects. However, a closer examination of the concentration effect on the measurement can broaden the applicability of this method. Penczek et al. (2015) determined a linear concentration dependence for PLA in benzene- $d_{6}$. This allowed to perform measurements at elevated sample concentration $\left(30 \mathrm{mg} \mathrm{mL}^{-1}\right)$, and extrapolate the diffusion coefficients back to the PLA calibration standard conditions of $<1 \mathrm{mg} \mathrm{mL}^{-1}{ }^{\left[{ }^{[20]}\right.}$ Following this line of thoughts, we investigated a range from 0.2 to $30.4 \mathrm{mg} \mathrm{mL}^{-1}$ for PET and PEF to evaluate the dependence of $D$ on concentration. Below $0.2 \mathrm{mg} \mathrm{mL}^{-1}$, the signal-to-noise was deteriorated such that the data was of insufficient quality for fitting the ST equation. Extending the measurement time up to 2 hours by a higher number of scan was unsuccessful to increase the data quality.

Increasing the sample concentration reduces the diffusion coefficient for PEF and PET

(Figure 6A), similar to previous reports on PLA in benzene- $d 6 .{ }^{[20]}$ Simply applying the earlier derived $\mathrm{M}_{\mathrm{w}}-D$ calibration (with samples at $0.4 \mathrm{mg} \mathrm{mL}^{-1}$ ), predicts increasingly higher molecular weights, introducing a systematic error (Figure 6B). A change of sample concentration by $1 \mathrm{mg} \mathrm{mL}^{-1}$ changes the $\mathrm{M}_{\mathrm{w}}$ prediction by $4 \%$ for PEF and $5 \%$ for PET, an 
important factor to consider for analysis reproducibility. The diffusion coefficients of PET samples at $0.4-0.7 \mathrm{mg} \mathrm{mL}^{-1}$ showed a variance of around $1 \%$ of the average, which falls into the same range as the general noise for repetitions of PET standard samples with a constant concentration of $0.4 \mathrm{mg} \mathrm{mL}^{-1}$. Since the error introduced by the concentration variation is systematic, the application of a simple correction factor, derived from the concentration dependence (Figure 6A), can compensate for the viscosity effect (Figure 6B). This extrapolates the results at higher concentrations back to calibration conditions at $0.4 \mathrm{mg} \mathrm{mL}^{-1}$ and enables molecular weight analysis at various concentrations.

We attribute the concentration dependence of the diffusion coefficient solely to an increase in viscosity rather than molecular crowding. Indeed, the molecular mean squared displacement, $z^{2}$, (equation 4) exhibits a linear trend for all tested concentrations of both PEF and PET samples (Figure 7). Such linearity indicates the absence of intermolecular interactions and thus an unhindered Gaussian diffusion regime. ${ }^{[29]}$ Therefore, concentrations up to $30 \mathrm{mg} \mathrm{mL}^{-1}$ are unaffected by molecular crowding and can be used for DOSY experiments. The slopes of those linear $z^{2}$ trends for both PEF and PET decrease with sample concentration, which again displays how $D$ is affected by viscosity.

$$
z^{2}=D t=D\left(\Delta-\frac{\delta}{3}\right)=\frac{-\ln \left(\frac{I}{I_{0}}\right)}{(\gamma \delta g \xi)^{2}}
$$

\subsection{Effect of DOSY time}

It is important to understand the governing factors of the DOSY experiment time to achieve reliable results, and to potentially reduce that time for applications where short analysis times 
are a key asset such as online measurements from polymer production streams. The DOSY experiment time itself mainly depends on the number of scans and the number of gradient strength increments. Good data quality (sufficient signal-to-noise) can be obtained by a limited numbers of scans provided that the sample concentration is increased. Together with the above extrapolations, this allows for an optimization of the analysis time within the concentration range 0.4 - $30 \mathrm{mg} \mathrm{mL}^{-1}$. Therefore, on the one hand, DOSY can be considered a sensitive technique to analyze limited sample quantities $\left(0.4 \mathrm{mg} \mathrm{mL}^{-1}\right)$ and on the other hand DOSY can be optimized for fast analysis, provided that enough sample is available. Our standard DOSY parameters result in an experiment of about 15 min (16 increments with 16 scans). For $0.4 \mathrm{mg} \mathrm{mL}^{-1}$, these settings delivered sufficient signal-to-noise to fit all data points along the DOSY signal decay curve, and were applied to establish the PET calibration curves as well as to evaluate PEF samples. When higher concentrations are applied, sufficient signal can be acquired during less scans, thus reducing the measurement time. Figure 8 shows examples for high and low concentration PEF samples analyzed with different DOSY sequences, where the number of scans and fitting increments were varied to minimize the required overall acquisition time. For low concentration samples, a reduced number of scans and increments sacrifices prediction accuracy. However, higher sample concentrations allow an accurate molecular weight prediction even with less scans. For example, at $9.6 \mathrm{mg} \mathrm{mL}^{-1}$ of PEF in TFA- $d$ with 2 scans and 8 gradient strength increments, the DOSY time per sample can be as low as 58 seconds, while retaining a high accuracy. Accuracy is expressed as the $\mathrm{M}_{\mathrm{w}}$ value estimated at shortened DOSY measurements relative to the value derived from the longest DOSY experiment, i.e. the one with highest signal-to-noise.

\subsection{Solvent selection}


In order to prove that solvent selection is not influencing the quality of NMR DOSY measurements, we conducted a brief study in HFIP- $d_{2}$, which features a higher viscosity than TFA- $d$. For that reason, diffusion is slower and the derived diffusion coefficients are consequently smaller. Figure $\mathbf{1 0}$ shows that the calibration in HFIP- $d_{2}$ results in the same trend of molecular weight predictions for PEF when compared with absolute molecular weight measurements using MALS.

\subsection{Challenges}

The diffusion time $\Delta$ itself affects signal quality since $\mathrm{T}_{1}$ relaxation (the thermodynamic selfequilibration of spins back from the $x$-y-plane to the $z$-axis) will reduce the signal proportional to the diffusion time ${ }^{[32]}$. On the other hand $T_{2}$ relaxation (dephasing of spins within the $x-y$-plane) plays a role during the application of the gradient for a time $\delta$. Since both $\Delta$ and $\delta$ are usually required to be set at high values for slowly diffusing (high molecular weight) molecules, relaxation processes have a profound deteriorating effect on data quality of such samples. ${ }^{[26]}$ Indeed, the largest molecular weight PET standard $\left(\mathrm{M}_{\mathrm{w}}=115,000 \mathrm{~g} \mathrm{~mol}^{-}\right.$ ${ }^{1}$ ) challenged us with the requirement for $\Delta=1400 \mathrm{~ms}$, resulting in significant signal loss. This could be compensated by using a slightly increased concentration of $0.68 \mathrm{mg} \mathrm{mL}-1$ (keeping other conditions the same), and applying the insights of concentration effects, as described earlier. Alternatively, measurement of larger molecules can be made feasible by tuning the measurement temperature. While this work was performed solely at $25^{\circ} \mathrm{C}$, higher temperatures will increase diffusional motion for all molecules, which results in reduced diffusion times required for full signal decay, which in turn will minimize the effect of signal loss due to $\mathrm{T} 1$ and $\mathrm{T} 2$ relaxation. We further optimized our system for the aromatic ring- 
protons due to their longer $\mathrm{T}_{2}$ relaxation time compared with the EG-protons, to minimize signal losses due to relaxation. EG-proton spins have a short $\mathrm{T}_{2}$ relaxation time, specifically about 6 times faster than furanic protons of PEF, which leads to partial signal loss in the more time-intensive DOSY experiments. This is evident from the reduced peak area ratio of the EG and furanic protons in the DOSY spectra (Furan:EG 1:1), the measurements of which were more time-intensive, compared with the expected one from standard ${ }^{1} \mathrm{H}$ NMR spectra (Furan:EG $=1: 2$, as given by the molecular structure of PEF).

\section{Conclusions}

DOSY NMR can be used to measure average molecular weights of PEF and PET polyesters, which present challenges to other established methods due to solubility issues. Predictions for $\mathrm{M}_{\mathrm{n}}$ and $\mathrm{M}_{\mathrm{w}}$ by DOSY match those of SEC-MALS closely. If the respective monomer chemical shifts differ from those of the polymer, concomitant conversion analysis of samples during reaction can be performed. Reproducibility and robustness of DOSY measurements can be ensured using convection compensated pulse programs and working at constant concentrations. However, the analysis time is mainly determined by sufficient signal-to-noise and thus can be as short as minutes when higher concentrations are applied and fewer scans are used. While concentrations up to $30 \mathrm{mg} \mathrm{mL}^{-1}$ showed Gaussian diffusion behavior and no intermolecular crowding effects, the impact of viscosity on concentration has to be determined for a given polymer-solvent system and accounted for when working at different concentrations for samples and calibrants. Cutting short the optimization of diffusion time $\Delta$ for each molecular weight by applying a constant (average) $\Delta$ can further reduce measurement time. Such fast DOSY analysis makes itself attractive to online measurement applications, for 
example in industrial production streams. Besides much shorter potential analysis time, DOSY can compete with size exclusion chromatography on solvent use $(<1 \mathrm{~mL}$ of deuterated trifluoroacetic acid compared with $<100 \mathrm{~mL}$ of hexafluoroisopropanol, HFIP) and a simpler experimental setup (one glass tube in the NMR magnet instead of various tubings, columns and detectors that are prone to failure upon HFIP use).

\section{Supporting Information}

Supporting Information is available from the Wiley Online Library or from the author.

Acknowledgements: This work is funded through project 16120.1-PFEN-IW by the Swiss Commission for Technology and Innovation (CTI) and SULZER. Jonathan de Roo thanks the FWO (Research Foundation Flanders) for his predoctoral fellowship. The fruitful discussions with Dr. René Verel at ETH Zurich and Dr. Liborio Ivano Costa at SULZER are kindly acknowledged.

Keywords: diffusion, DOSY NMR, molecular weight analysis, furanic polyesters, poly(ethylene furanoate)

[1.] J. J. Bozell, G. R. Petersen, Green Chem. 2010, 12, 539.

[2.] A. Gandini, D. Coelho, M. Gomes, B. Reis, A. Silvestre, J. Mater. Chem. 2009, 
$19,8656$.

[3.] A. Gandini, Biocatal. Polym. Chem. 2010, 1, doi:10.1002/9783527632534.ch1.

[4.] R. J. I. Knoop, W. Vogelzang, J. van Haveren, D. S. van Es, J. Polym. Sci. Part A Polym. Chem. 2013, 51, 4191.

[5.] X. Lou, J. L. J. Van van Dongen, H. M. Janssen, R. F. M. Lange, J. Chromatogr. A 2002, 976, 145.

[6.] S. Thiyagarajan et al., Green Chem. 2014, 16, 1957.

[7.] E. De Jong, M. a. Dam, L. Sipos, G. J. M. Gruter, Biobased Monomers, Polym. Mater. 2012, 1105, 1.

[8.] S. K. Burgess, O. Karvan, J. R. Johnson, R. M. Kriegel, W. J. Koros, Polym. (United Kingdom) 2014, 55, 4748.

[9.] S. K. Burgess et al., Macromolecules 2014, 47, 1383.

[10.] D. Pfister, G. Storti, F. Tancini, L. I. Costa, M. Morbidelli, Macromol. Chem. Phys. 2015, 216, 2141.

[11.] L. I. Costa et al., 2013.

[12.] L. I. Costa et al., 2013.

[13.] J. C. Morales-Huerta, A. Martínez de Ilarduya, S. Muñoz-Guerra, Polymer (Guildf). 2016, 87, 148.

[14.] A. Moroni, T. Havard, Chromatogr. Polym. 1999, 249.

[15.] W. Li, H. Chung, C. Daeffler, J. A. Johnson, R. H. Grubbs, Macromolecules 2012, 45, 9595 .

[16.] J. De Roo et al., J. Am. Chem. Soc. 2014, 136, 9650 - 9657.

[17.] L. Van Lokeren et al., Chem. - A Eur. J. 2007, 13, 6957.

[18.] J. a Jones, D. K. Wilkins, L. J. Smith, C. M. Dobson, J. Biomol. NMR 1997, 10, 199.

[19.] B. Antalek et al., Magn. Reson. Chem. 2002, 40, 60. 
[20.] S. Penczek, P. Lewinski, S. Sosnowski, S. Kazmierski, Polym. Chem. 2015, 6, 4353.

[21.] A. Chen, D. Wu, C.S. Johnson. J. Am. Chem. Soc. 1995, 117, 7965-7970.

[22.] D. Sinnaeve, Concepts Magn. Reson. Part A, 2012, 40, 39.

[23.] D. J. Brunelle, J. E. Bradt, J. Serth-Guzzo, T. Takekoshi, T. L. Evans, E. J. Pearce, Am. Chem. Soc. Polym. Prepr. Div. Polym. Chem. 1997, 38, 381.

[24.] E. O. Stejskal, J. E. Tanner, J. Chem. Phys. 1965, 42, 5.

[25.] W. S. Price, Concepts Magn. Reson. 1998, 10, 197.

[26.] T. D. W. Claridge, High-Resolution NMR Tech. Org. Chem. 2009, 27, 303.

[27.] M. a. Connell, P.J. Bowyer, P. A. Bone, A. L. Davis, A. G. Swanson, M. Nilsson, G. Morris, J. Magn. Reson. 2009, 198, 121.

[28.] N. E. Kuz'mina, S. V Moiseev, V. I. Krylov, V. A. Yashkir, V. A. Merkulov, J. Anal. Chem. 2015, 70, 843.

[29.] G. Wolf, E. Kleinpeter, Langmuir 2005, 21, 6742.

[30.] B. Antalek, Concepts Magn. Reson. 2002, 14, 225.

[31.] R. Kerssebaum, G. Salnikov, 2006.

[32.] S. Spiegel, K. Schmidt-Rohr, C. Boeffel, H. W. Spiess, Polymer (Guildf). 1993, $34,4566$. 

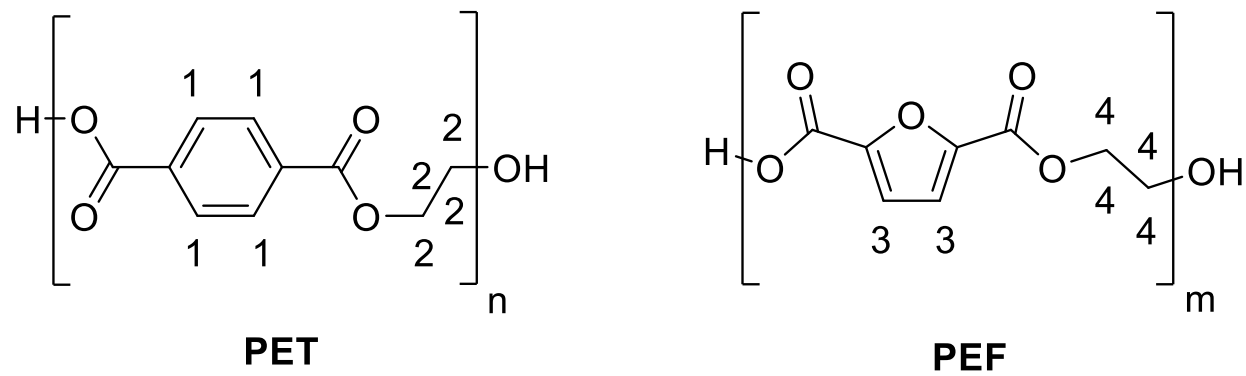

PEF

Figure 1. Molecular structures of PET (left) and PEF (right) 


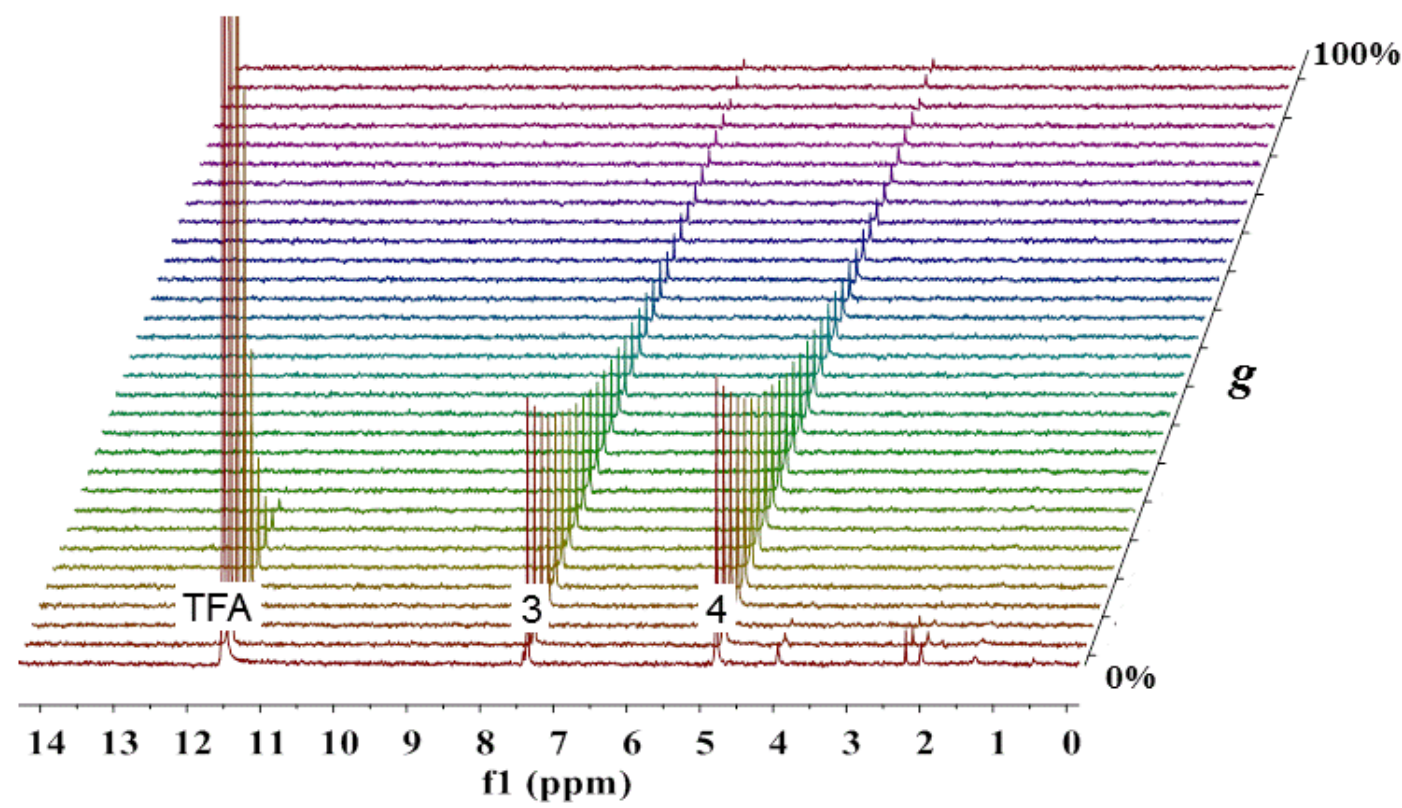

Figure 2. Stacked increments of ${ }^{1} \mathrm{H}$ NMR spectra of PEF (7.46 ppm $=3=$ Furan, $4.88 \mathrm{ppm}=$ $4=$ Ethylene Glycol $)$ in TFA- $d(11.7 \mathrm{ppm}=$ TFA $)$ with increasing gradient strength $g$.

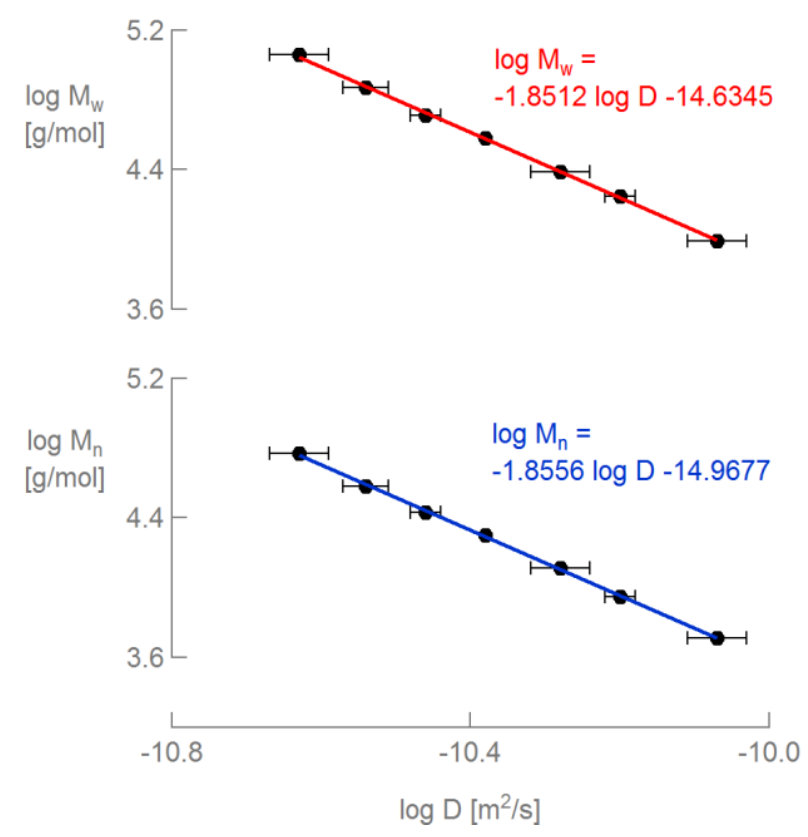

Figure 3. DOSY calibration curve of PET standards $\left(\mathrm{M}_{\mathrm{w}}=9,870 \mathrm{~g} \mathrm{~mol}^{-1}-115,000 \mathrm{~g} \mathrm{~mol}^{-1}\right)$ in TFA- $d$ derived from fully $(5 \%)$ attenuated aromatic proton signal decay curves. Error bars were calculated using t-statistics on the variance of $>3$ repetitions per sample. 

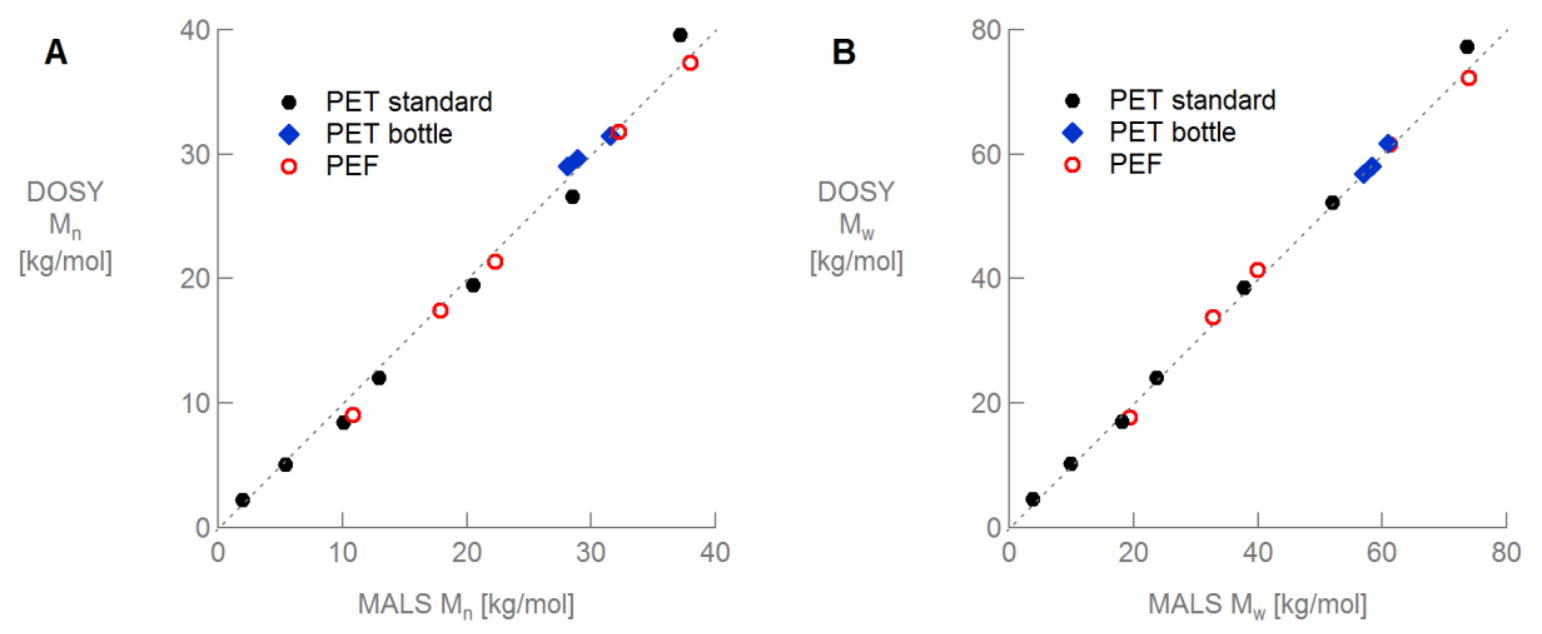

Figure 4. Comparison of A) $\mathrm{M}_{\mathrm{n}}$ and B) $\mathrm{M}_{\mathrm{w}}$ analysis for PET standards, PET bottles and PEF samples by NMR-DOSY in TFA-d and SEC-MALS in HFIP.

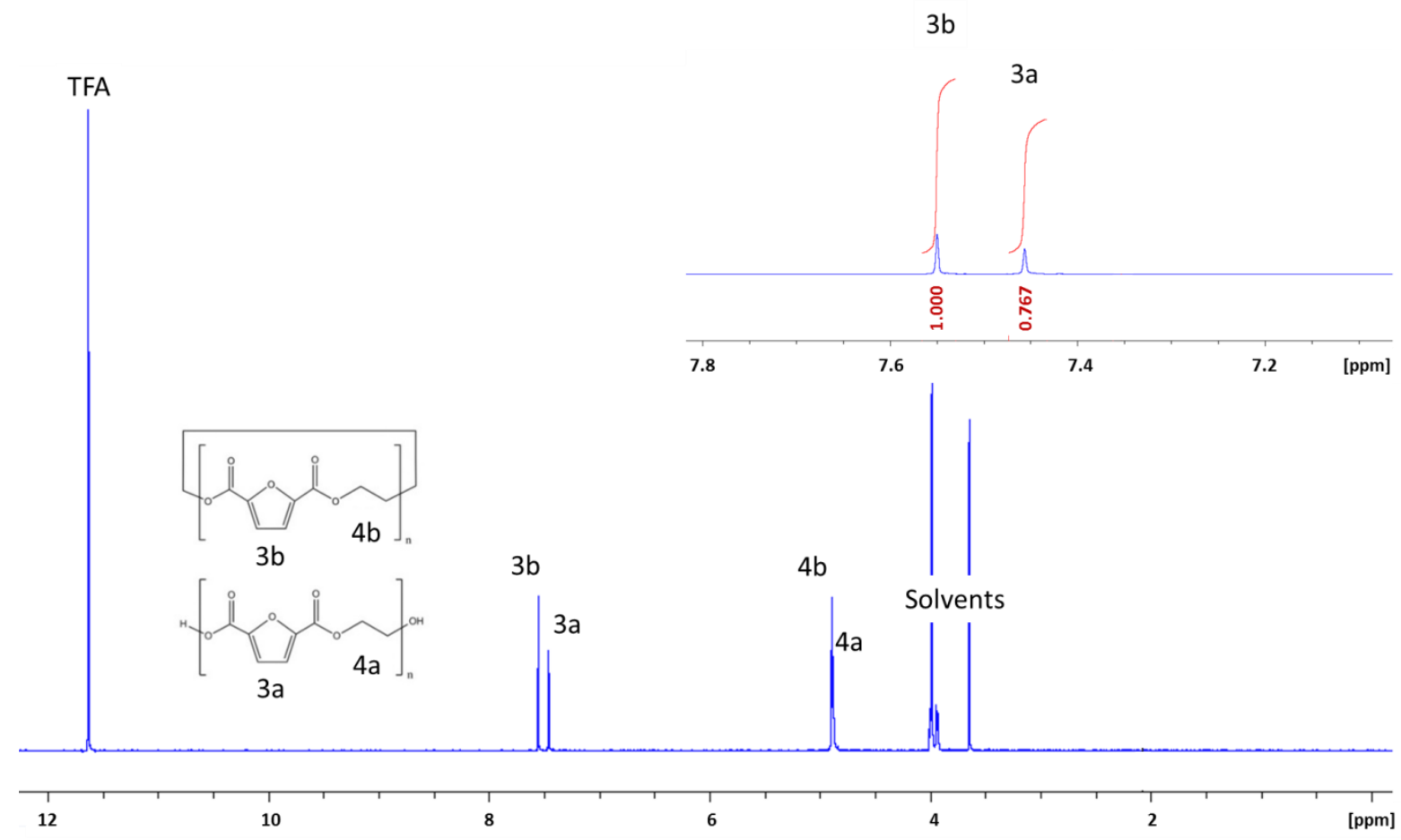

Figure 5. ${ }^{1} \mathrm{H}$ NMR of a PEF sample taken from the ring-opening polymerization reactor. The separated chemical shifts of the furanic unit and the Ethylene Glycol incorporated in the PEF polymer $(3 \mathrm{a}, 4 \mathrm{a})$ and the cyclic monomer $(3 \mathrm{~b}, 4 \mathrm{~b})$ respectively, can be used for individual molecular weight analysis. 

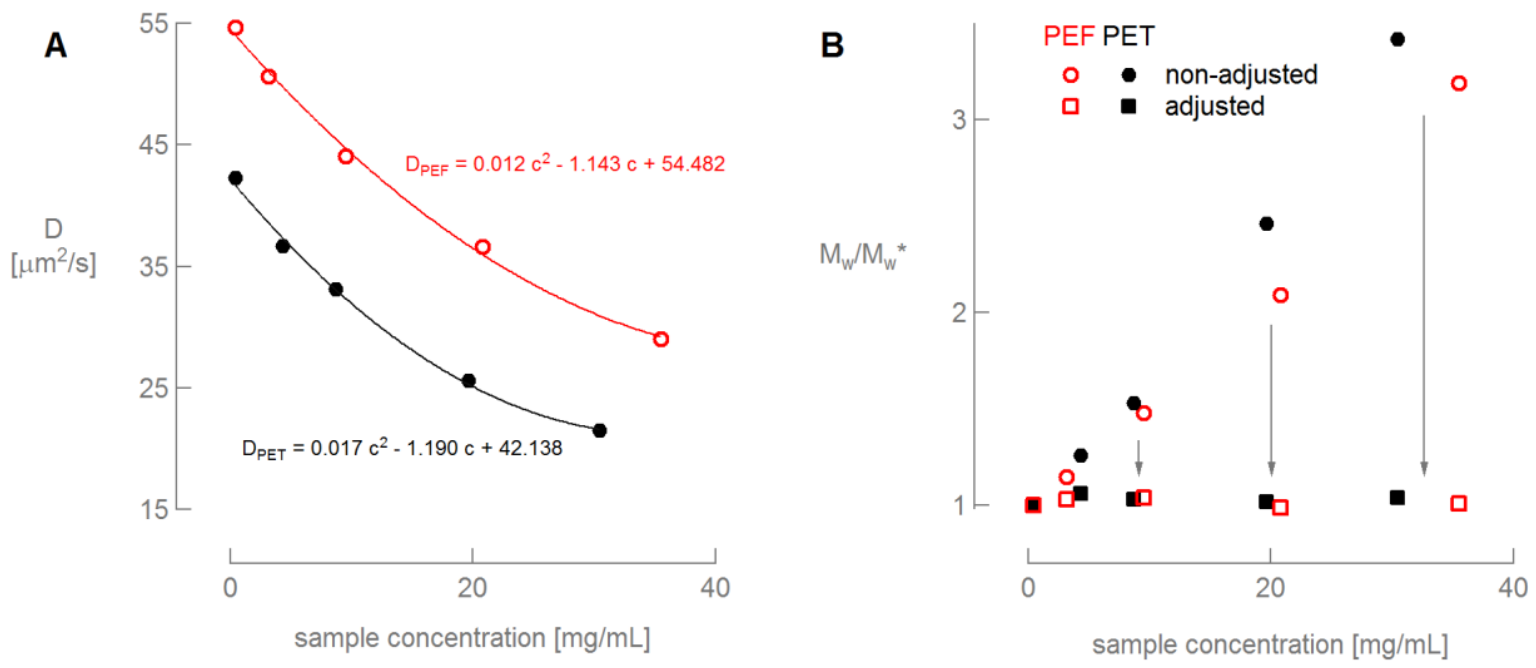

Figure 6. Effect of sample concentration on diffusion (A) and $\mathrm{M}_{\mathrm{w}}$ prediction (B) for PET (•) and PEF (O) samples. $\mathrm{M}_{\mathrm{w}} / \mathrm{M}_{\mathrm{w}}{ }^{*}$ is the ratio of the concentration dependent $\mathrm{M}_{\mathrm{w}}$ prediction relative to that at $0.4 \mathrm{mg} \mathrm{mL}^{-1} \mathrm{~g} \mathrm{~mol}^{-1}$ concentration. Predictions of higher concentration samples were adjusted (B) using the observed dependence of D on sample concentration for

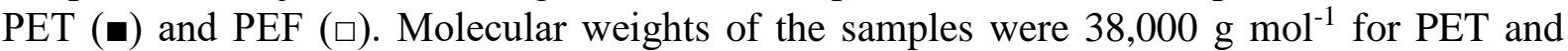
23,000 $\mathrm{g} \mathrm{mol}^{-1}$ for PEF, respectively.

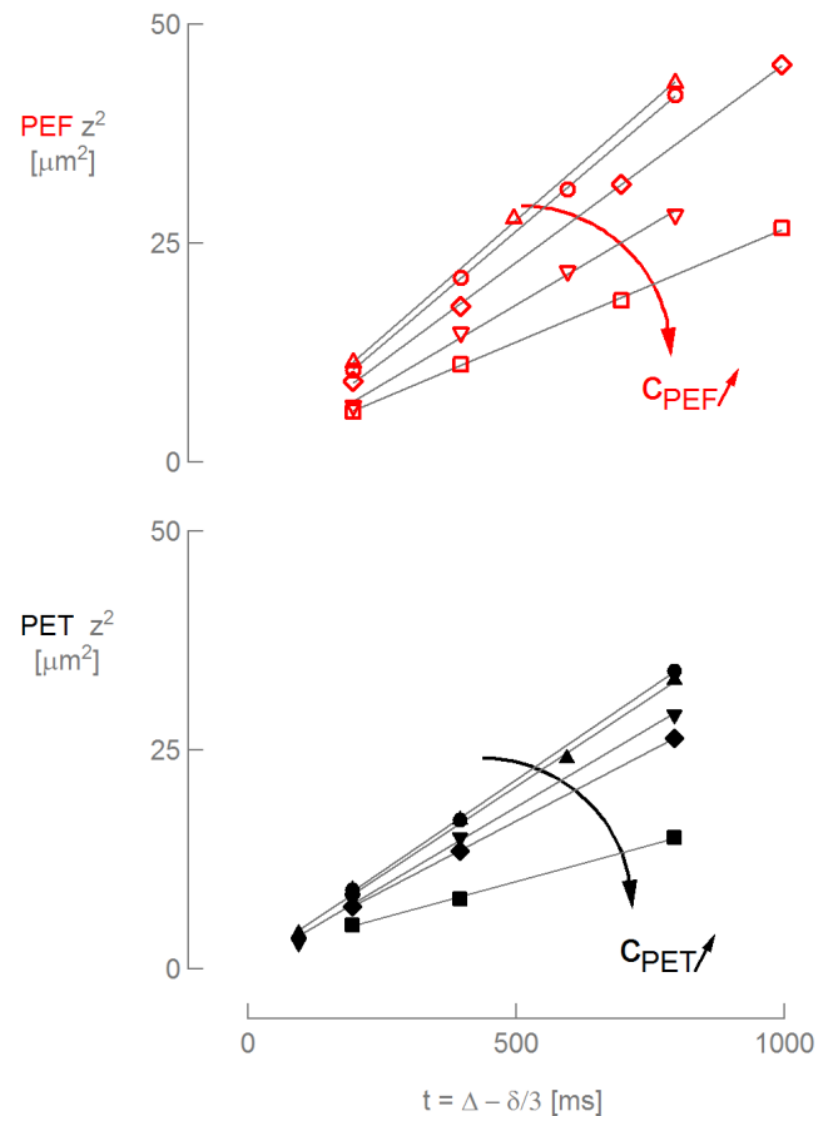

Figure 7. Evaluation of unhindered Gaussian diffusion conditions via mean square displacement $\mathrm{z}^{2}$ analysis. Tested concentrations were $0.4,3.1,9.5,20.8,35.5 \mathrm{mg} \mathrm{mL}^{-1}$ for PEF and 0.4, 0.7, 4.3, 8.7, $30.4 \mathrm{mg} \mathrm{mL}^{-1}$ for PET. 


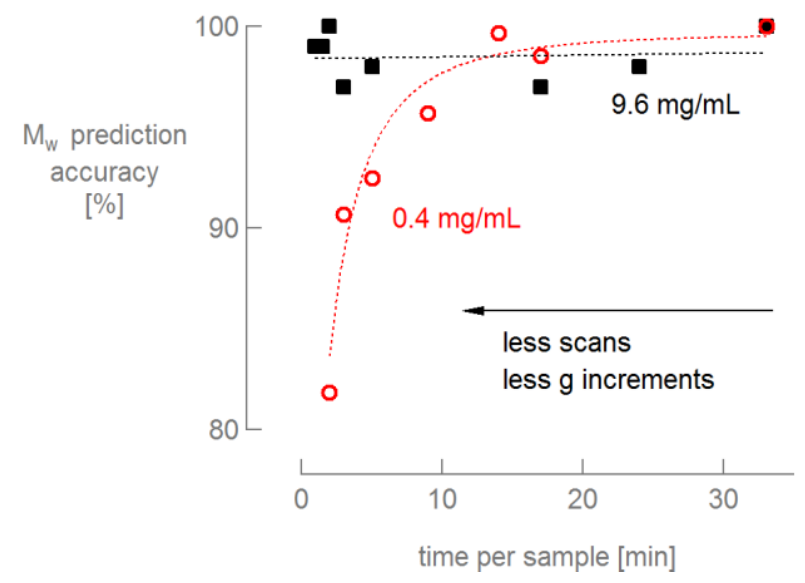

Figure 8. Influence of DOSY measurement time, as a result of the applied number of scans and field strength gradient (g) increments, on the accuracy of weight-based molecular weight $\left(\mathrm{M}_{\mathrm{w}}\right)$ prediction for high $\left(\bullet, 9.6 \mathrm{mg} \mathrm{mL}^{-1}\right)$ and low $\left(\bullet, 0.4 \mathrm{mg} \mathrm{mL}^{-1}\right)$ concentration PEF samples. The lines are to guide the eye.

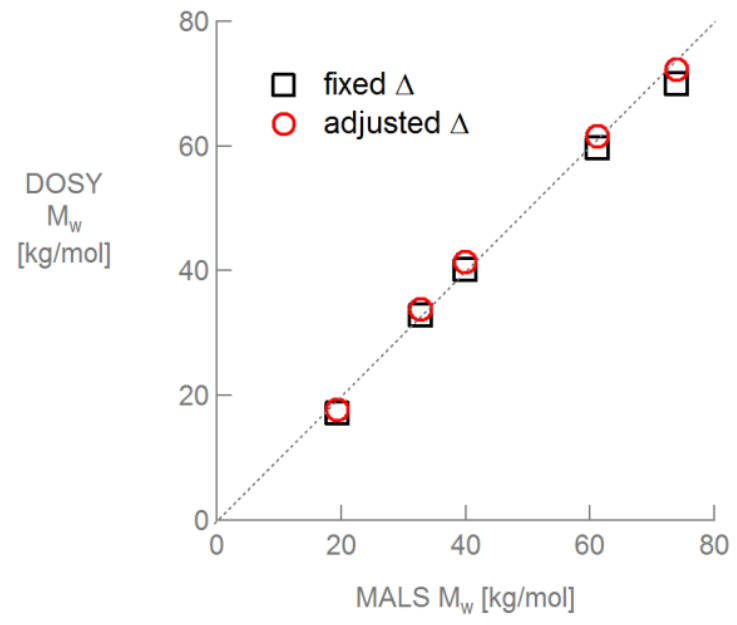

Figure 9. PEF samples analyzed with PET calibrations derived from data obtained using fixed and adjusted diffusion times $\Delta$. 


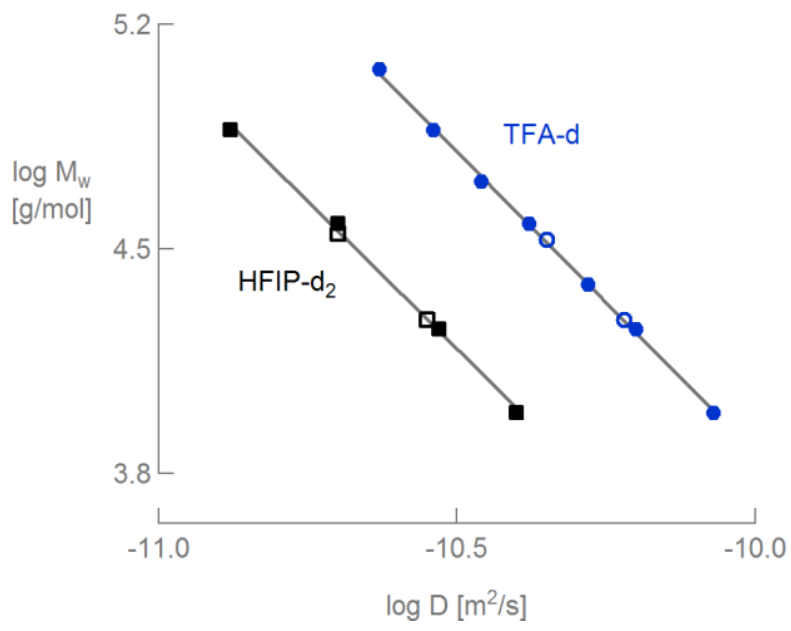

Figure 10. Comparison of PET calibrations in more viscous HFIP- $d_{2}(\bullet)$ and TFA-d $(\bullet)$, and the resulting $\mathrm{M}_{\mathrm{w}}$ predictions for two PEF samples in HFIP- $d_{2}(\square)$ and TFA- $d(0)$. Predicted $\mathrm{M}_{\mathrm{w}}$ were 18,970 $\mathrm{g} \mathrm{mol}^{-1}$ and 35,290 $\mathrm{g} \mathrm{mol}^{-1}$ (口) compared with MALS values 19,150 $\mathrm{g} \mathrm{mol}^{-1}$ and $33,850 \mathrm{~g} \mathrm{~mol}^{-1}(\circ)$, respectively. 
Table 1. Number-average and weight-average molecular weights, $M_{n}$ and $M_{w}$, respectively, and polydispersity values (PDI=M $\left./ M_{n}\right)$ derived from SEC-MALS and DOSY NMR for PET standards, commercial PET bottle samples and synthesized PEF products.

\begin{tabular}{|c|c|c|c|c|c|c|c|}
\hline & $\begin{array}{l}\text { SEC-MA } \\
\text { Mn } \\
{\left[\mathrm{g} \mathrm{mol}^{-1}\right]}\end{array}$ & $\begin{array}{l}\mathrm{M}_{\mathrm{w}} \\
{\left[\mathrm{g} \mathrm{mol}^{-1}\right]}\end{array}$ & $\begin{array}{l}\text { PDI } \\
{[-]}\end{array}$ & $\begin{array}{l}\text { DOSY N } \\
\text { Mn } \\
{\left[\mathrm{g} \mathrm{mol}^{-1}\right]}\end{array}$ & $\begin{array}{l}\mathrm{M}_{\mathrm{w}} \\
{\left[\mathrm{g} \mathrm{mol}^{-1}\right]}\end{array}$ & $\begin{array}{l}\text { PDI } \\
{[-]}\end{array}$ & $\begin{array}{l}D \\
{\left[\mathbf{m}^{2} \mathbf{s}^{-1}\right]}\end{array}$ \\
\hline $\begin{array}{l}\text { PET standards } \\
\text { PSS-pet3.5k } \\
\text { PSS-pet10k } \\
\text { PSS-pet18k } \\
\text { PSS-pet25k } \\
\text { PSS-pet35k } \\
\text { PSS-pet50k } \\
\text { PSS-pet75k }\end{array}$ & $\begin{array}{l}2000 \\
5420 \\
10050 \\
12950 \\
20500 \\
28500 \\
36360 \\
\end{array}$ & $\begin{array}{l}3760 \\
9900 \\
18190 \\
23720 \\
37770 \\
51920 \\
73230 \\
\end{array}$ & $\begin{array}{l}1.88 \\
1.83 \\
1.81 \\
1.83 \\
1.84 \\
1.82 \\
2.01 \\
\end{array}$ & $\begin{array}{l}2206 \\
5053 \\
8478 \\
12055 \\
19499 \\
26594 \\
39587 \\
\end{array}$ & $\begin{array}{l}4537 \\
10240 \\
17010 \\
24040 \\
38540 \\
52270 \\
77240 \\
\end{array}$ & $\begin{array}{l}2.06 \\
2.03 \\
2.01 \\
1.99 \\
1.98 \\
1.97 \\
1.95 \\
\end{array}$ & $\begin{array}{l}1.33 \cdot 10^{-10} \\
8.54 \cdot 10^{-11} \\
6.47 \cdot 10^{-11} \\
5.36 \cdot 10^{-11} \\
4.14 \cdot 10^{-11} \\
3.51 \cdot 10^{-11} \\
2.84 \cdot 10^{-11}\end{array}$ \\
\hline $\begin{array}{l}\text { Commercial PET bottles } \\
\text { PET bottle } 1 \\
\text { PET bottle } 2 \\
\text { PET bottle } 3 \\
\end{array}$ & $\begin{array}{l}28061 \\
28879 \\
31515 \\
\end{array}$ & $\begin{array}{l}57050 \\
58380 \\
60900 \\
\end{array}$ & $\begin{array}{l}2.03 \\
2.02 \\
1.93 \\
\end{array}$ & $\begin{array}{l}29020 \\
29650 \\
31500 \\
\end{array}$ & $\begin{array}{l}56875 \\
58110 \\
61753 \\
\end{array}$ & $\begin{array}{l}1.96 \\
1.96 \\
1.96 \\
\end{array}$ & $\begin{array}{l}3.35 \cdot 10^{-11} \\
3.31 \cdot 10^{-11} \\
3.21 \cdot 10^{-11}\end{array}$ \\
\hline $\begin{array}{l}\text { PEF synthesis products } \\
\text { PEF1 } \\
\text { PEF2 } \\
\text { PEF3 } \\
\text { PEF4 } \\
\text { PEF5 } \\
\text { PEF from reactor }(X=43.4 \%)\end{array}$ & $\begin{array}{l}10600 \\
17490 \\
21760 \\
31490 \\
34110 \\
16100\end{array}$ & $\begin{array}{l}19420 \\
32740 \\
39910 \\
61130 \\
72420 \\
31900\end{array}$ & $\begin{array}{l}1.83 \\
1.87 \\
1.83 \\
1.94 \\
1.94 \\
1.98\end{array}$ & $\begin{array}{l}9099 \\
17454 \\
21397 \\
31807 \\
37333 \\
16600\end{array}$ & $\begin{array}{l}17670 \\
33850 \\
41480 \\
61600 \\
72270 \\
32200\end{array}$ & $\begin{array}{l}1.94 \\
1.94 \\
1.94 \\
1.94 \\
1.94 \\
1.94\end{array}$ & $\begin{array}{l}6.31 \cdot 10^{-11} \\
4.44 \cdot 10^{-11} \\
3.98 \cdot 10^{-11} \\
3.22 \cdot 10^{-11} \\
2.95 \cdot 10^{-11} \\
4.57 \cdot 10^{-11}\end{array}$ \\
\hline
\end{tabular}




\section{Table of contents entry}

In this work, diffusion (DOSY) ${ }^{1} \mathrm{H}$ NMR was explored as an alternative, reliable and fast method to analyze molecular weights of polyethylene furanoate (PEF). Excellent agreement of DOSY predictions with the absolute $\mathrm{M}_{\mathrm{n}}$ and $\mathrm{M}_{\mathrm{w}}$ values from light scattering and optimized DOSY analysis times (down to $1 \mathrm{~min}$ ) underlined the attractiveness of DOSY as a powerful and fast tool for molecular weight analysis in the laboratory as well as in industrial process applications.

J.-G. Rosenboom, J. de Roo, G. Storti, M. Morbidelli*

Diffusion (DOSY) ${ }^{1} \mathrm{H}$ NMR as an alternative method for molecular weight determination of polyethylene furanoate (PEF) polyesters

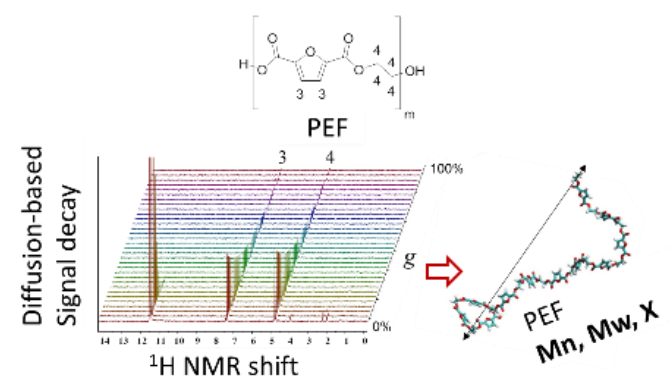


Copyright WILEY-VCH Verlag GmbH \& Co. KGaA, 69469 Weinheim, Germany, 2013.

\section{Supporting Information}

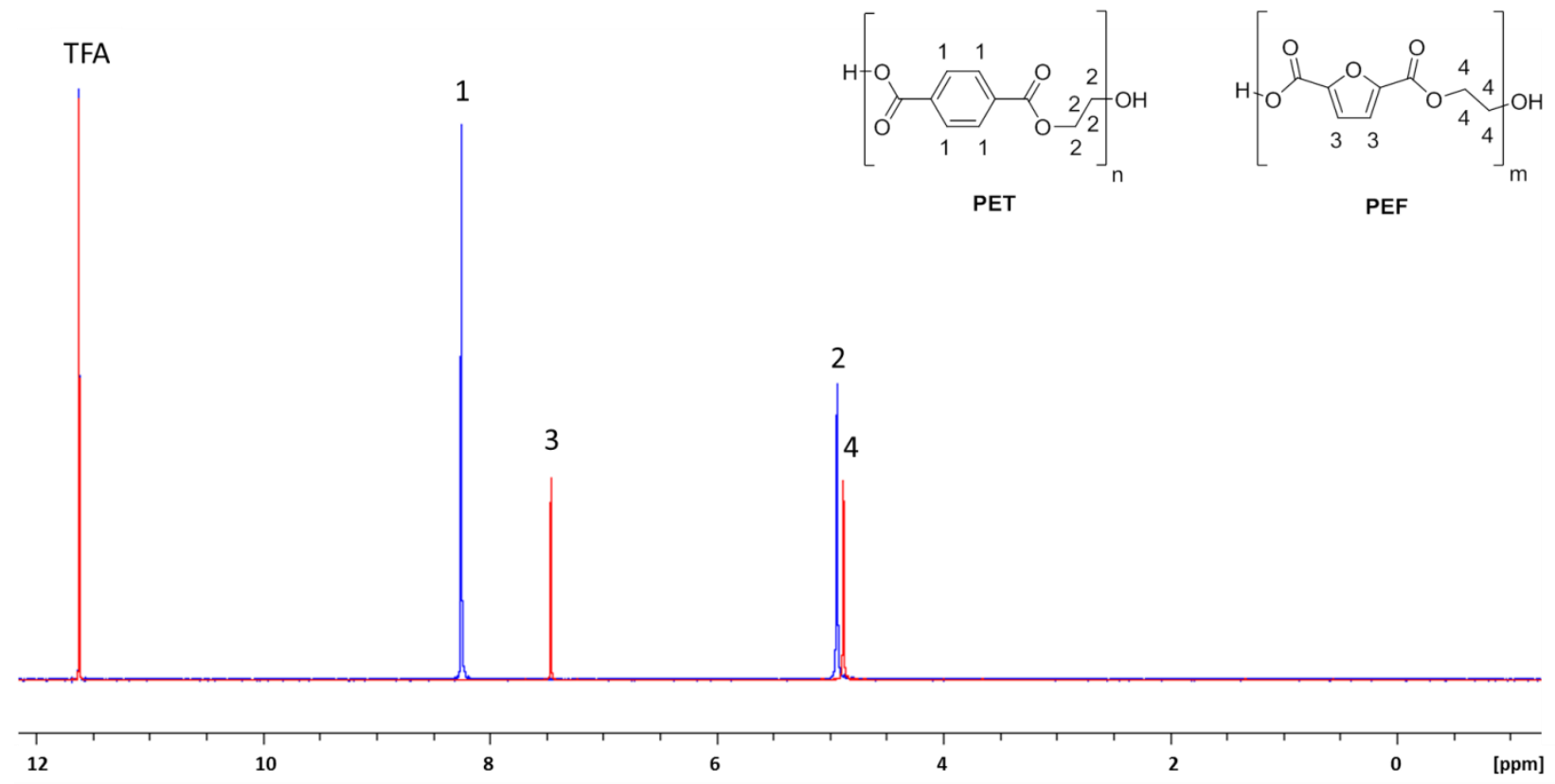

Figure S1. ${ }^{1} \mathrm{H}$ NMR spectra for PET and PEF in TFA-d.

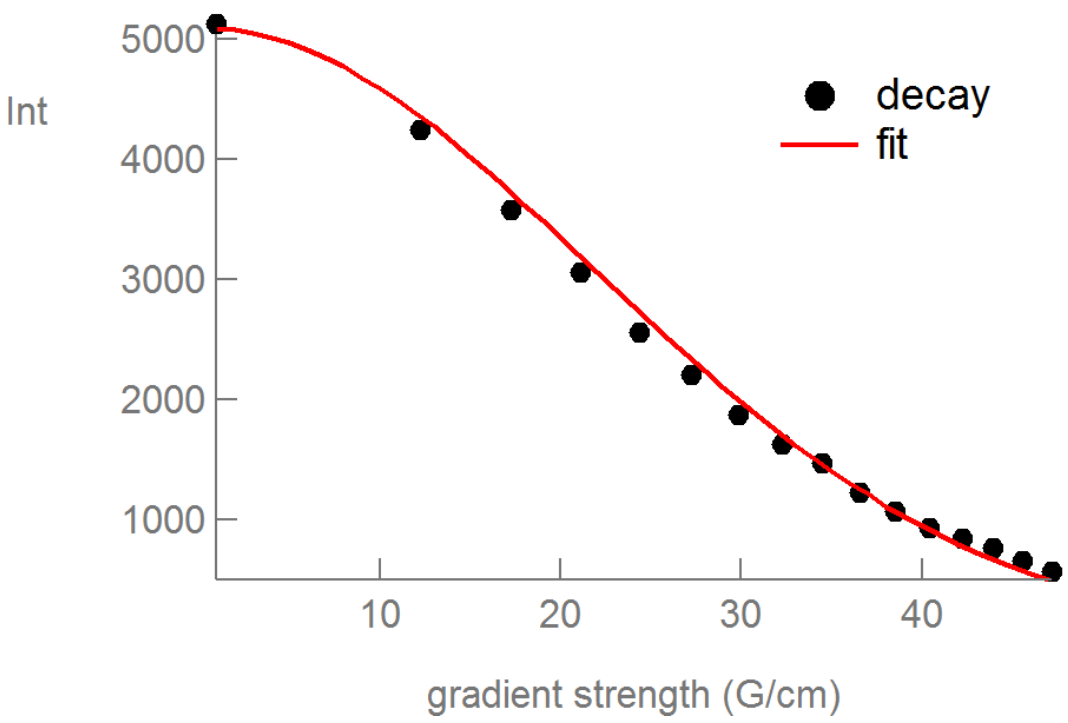

Figure S2. Exemplary signal intensity (Int) decay curve of furan protons (chemical shift = $7.46 \mathrm{ppm}$ ) derived from DOSY on a PEF sample $\left(\bullet\right.$, MALS $\left.\mathrm{M}_{\mathrm{w}}=39910 \mathrm{~g} / \mathrm{mol}\right)$ using diffusion time $\Delta=600 \mathrm{~ms}$. The data was fitted (-) with the Stejskal-Tanner equation (equation 1) to derive a diffusion coefficient $\mathrm{D}=3.982 \cdot 10^{-11}$, which using the PET calibration (Figure 3) resulted in an $\mathrm{M}_{\mathrm{w}}=41480 \mathrm{~g} / \mathrm{mol}$. 
Diffusion (DOSY) 1H NMR as an alternative method for molecular weight determination of polyethylene furanoate (PEF) polyesters

Jan-Georg Rosenboom, Jonathan de Roo, Giuseppe Storti, Massimo Morbidelli* 